\title{
A PEDAGOGIA TEATRAL COMO CUIDADO DE SI EM MEIO ÀS EXPERIMENTAÇÕES DA MEMÓRIA CORPORAL PROPOSTAS POR LYGIA CLARK
}

\section{THEATER PEDAGOGY AS A CARE OF YOU AMONG BODY MEMORY EXPERIMENTS PROPOSED BY LYGIA CLARK}

Ivan Gemaque de Paula interconexo@hotmail.com Acadêmico do Curso de Licenciatura em Teatro da Universidade Federal do Amapá

\begin{abstract}
Resumo:
É feita aqui uma investigação a respeito do trabalho artístico de Lygia Clark, intitulado Estruturação do Self, que apresenta uma concepção de arte propondo ao artista um papel de terapeuta que conduz o sujeito a ter consciência das memórias de seu corpo, buscando-se estabelecer um diálogo com o Teatro como pedagogia, partindo do pressuposto de que o conteúdo deste componente curricular não deve ser visto apenas como preparação de espetáculo ou como ensino da história do Teatro, mas sim como possibilidade de instigar atores e não atores a cuidarem de si, compreendendo o termo cuidado de si aqui a partir de proposição pedagógica apontada por Gilberto Icle (2009) como Pedagogia Teatral que inclui o outro no cuidado de si.
\end{abstract}

Palavras-Chaves: Corpo, Pedagogia Teatral, Cuidado de si.

\begin{abstract}
:
An investigation is made here about Lygia Clark's artistic work, entitled Structuring the Self, which presents a conception of art proposing to the artist a role of therapist that leads the subject to be aware of the memories of his body, seeking to establish a dialogue with the Theater as pedagogy, assuming that the content of this curricular component should not be seen only as a preparation of the show or as teaching the history of the Theater, but as a possibility to instigate actors and not actors to take care of themselves, understanding the term self-care here from the pedagogical proposition pointed by Gilberto Icle (2009) as Theatrical Pedagogy that includes the other in selfcare.
\end{abstract}

Keywords: Body, Theatrical Pedagogy, Self Care.

De início pretendia entender se o Teatro, como componente curricular, poderia ajudar a melhorar a relação professor aluno na sala de aula. No entanto, não tinha muito claro que metodologia empregar para fazer uma intervenção que pudesse abranger o universo de uma pesquisa como essa que nem tinha certeza se seria necessária.

Mas que neste sentido, Preocupa-me a forma como as pessoas se relacionam no lugares em que convivem, pois muitas vezes, concordando com Nicastro (2006), mesmo que estejam ocupando o mesmo lugar, que no caso específico aqui trata-se da escola, esse lugar está caracterizado como um não lugar ou como um espaço vazio em que as pessoas (professores e 79

IAÇÁ: Artes da Cena | Vol. II| n. 2 | ano 2019 
funcionários da escola), findam por não encontrar-se de tão absortas que estão em seu fazer mecânico na rotina de seu trabalho, fazer esse que, repetido inúmeras vezes, nem ao menos se reserva um tempo para que se questione sobre o que se está fazendo.

A importância de se fazer uma pesquisa que busque entender a possibilidade de o Teatro poder instigar as pessoas a entender a importância do cuidar de si e do cuidar do outro a partir da consciência que tenham de seu próprio corpo e que isso não estaria restitro apenas ao âmbito da escola, mas pode/deve ser experimentado com quaisquer pessoas, de forma coletivas ou individuais estabelecendo inúmeras sensações advindas por meio da memória corporal.

Por isso é uma proposta de se pensar formas de convivência que instiguem o cuidar de sí na perspectiva do cuidar do outro. O professor, pesquisador, diretor e ator de teatro da Universidade Federal do Rio Grande do Sul - UFRGS, Gilberto Icle (2010), nos traz a reflexão de como o trabalho com o Teatro pode proporcionar, a quem dele participa, a aprendizagem e o desenvolvimento de si na vivência com o outro. Este autor teceu uma extensa pesquisa no que ele nomeou como Pedagogia Teatral como cuidado de si.

Assim, sob influência dos escritos de Gilberto Icle (2010), procurei munir-me de material que proporcionasse entender como se poderia propor um processo de investigação que trilhasse pela relação do cuidado de si em numa perspectiva mais voltada para uma pedagogia dos corpos em relação com outros corpos e com o próprio ambiente em que estariam inseridos.

Nesse sentido, estabelece-se como foco da pesquisa o entender como o artista pode ser capaz de auxiliar as pessoas na tarefa do cuidado de si por via da conscientização corporal.

A proposição da Estruturação do Self ${ }^{1}$, da pintora e escultora brasileira Lygia Clark ${ }^{2}$ (Belo Horizonte, 1920 - Rio de Janeiro, 1988), pressupõe uma experimentação por meio da

\footnotetext{
1 Método terapêutico desenvolvido por Lygia Clark que envolve o Objeto Relacional que é a designação genérica atribuída pela artista a todos os elementos que utilizava nas sessões de Estruturação do Self - trabalho praticado de 1976 a 1988, no qual culminam as investigações da artista que envolvem o receptor e convocam sua experiência corporal como condição de realização da obra.
}

2 Lygia Clark, pseudônimo de Lygia Pimentel Lins (Belo Horizonte, 23 de outubro de 1920 - Rio de Janeiro, 25 de abril de 1988) foi uma pintora e escultora brasileira contemporânea que se auto intitulava "não artista". Lygia Clark iniciou seus estudos artísticos em 1947, no Rio de Janeiro, sob a orientação de Roberto Burle Marx e Zélia Salgado. Em 1950, viajou a Paris onde estudou com Arpad Szènes, Dobrinsky e Léger. A artista dedicou-se ao estudo de escadas e desenhos de seus filhos, assim como realizou os seus primeiros óleos. Após sua primeira exposição individual, no Institut Endoplastique, em Paris, no ano de 1952, a artista retornou ao Rio de Janeiro e expõe no Ministério da Educação e Cultura. 
conscientização dos corpos em relação aos outros e aos elementos que estão a sua volta e como isso pode dialogar com a perspectiva pedagógica apontada por Icle (2006), instigando as pessoas a preocuparem-se com o cuidado de si na convivência (experiência corporal) com o outro.

\section{A conscientização do corpo segundo Lygia Clark}

Segundo Almeida (2013), foi em 1966 o ano em que Clark inaugurou sua fase dita sensorial - que mais tarde ficaria conhecida como "Nostalgia do Corpo" em que a artista propõe o momento do ato como campo de experiência. Num mundo em que o homem tornou-se estranho a seu trabalho, ela propõe que o incitemos, pela experiência corporal "Objeto Relacional", a tomar consciência da alienação em que vive.

Clark compreende o corpo como sendo uma descoberta que o próprio indivíduo passa a ter de seu próprio corpo em contato com outros corpos, passando também a experimentar a sensação desses corpos em contato com o seu, num processo que tem efeito diretamente em seu centro psíquico. As pessoas conhecerem os seus corpos, como são deslocados no espaço, como são vistos e como é tratado por si e pelos outros com os quais convive.

O primeiro momento de consciência do corpo para Clark, segundo Almeida (2013), é a consciência que o sujeito tem do próprio corpo que, com ele, nele e por meio dele produz um estado singular de ser; ou seja, do sujeito perceber a existência de seu próprio corpo, reconhecê-lo como si mesmo, seu modo de agir, sua corporeidade imediata, manifestada na aceitação que tem de si, da sua materialidade ou organicidade. Sentir-se pele. Reconhecer-se a si mesmo no corpo e na forma de corpo, reconhecer-se, portanto, como corpo.

Segundo Almeida (2013), no estudo que fez sobre o a Estruturação do Self de Clark, a experiência com o corpo consiste em que cada pequeno gesto possa ser sentido como estando carregado de significado, não bastando portanto, a si mesmo, mas com o objetivo de construir um pensamento. Sendo uma obra literalmente reflexiva, no sentido de produzir um reflexo, uma reação, um caminho de volta que vai da retina para a consciência do corpo, da simples contemplação à interação ampliada pelo aspecto físico, orgânico, biológico. Depois, da percepção do próprio corpo para a introspecção, ou seja, para a busca de uma interioridade individual, para um retorno ao si próprio, seja intelectual e ou emotivo.

Outro momento de consciência corporal apontado por Almeida (2013), a partir do trabalho de Clark, corresponde ao movimento contrário ao primeiro, pois ao invés da 81 
consciência em direção ao corpo, tem-se agora o corpo como origem da própria consciência corporal. Consiste em uma consciência encarnada, que provém do corpo e é por ele constituída; a consciência que se faz por meio dos sentidos e das sensações, que existe porque existe um corpo sensível e ele está posto em relação com outros corpos.

A comunicação do corpo com outros sujeitos e por conseguinte com outros corpos pressupõe a incorporação do outro no sentido de abrir seu corpo a ele, de aprendê-lo afetivamente e é isso que segundo Almeida (2013) que será a base da Estruturação do Self que será buscado por Clark rumo ao cerne do sujeito, buscando outro corpo, escondido sob a pele, impregnado na carne, que vive no mundo protegendo sua identidade sob uma máscara, mas que ao serem colocados com outros corpos trazem à tona uma memória afetiva, a qual não se manifestaria pela palavra.

\section{O discurso de Lygia Clark sobre a Estruturação do Self}

Clark(1980) descreve o processo de Estruturação do Self minuciosamente, falando de como procura acomodar o individuo submetido à experiência com o que ela chama de Objetos Relacionais - estruturas elaboradas pela própria artista que tem como função ocupar todos os espaços do corpo do indivíduo com objetos de diversas texturas e densidades ao mesmo tempo em que vai massageando longamente e lentamente todos os espaços que sente estarem vazios.

\footnotetext{
A pessoa deita-se sumariamente vestida sobre um grande colchão de plástico recheado de isopor, coberto por um lençol solto. Com seu peso a pessoa já abre sulcos no colchão dentro dos quais seu corpo se acomoda. Massageio longamente a cabeça e a comprimo com as mãos. Pego com as mãos todo o corpo, junto as articulações docemente com firmeza, o que dá a muitos a sensação de - colar ou - soltar pedaços do corpo. Para outros o toque tem o poder de - fechar os - buracos do corpo ou deslocá-los para outras áreas. Trabalho o corpo inteiro com as - almofadas leves, friccionando longamente a planta dos pés e a palma das mãos. Coloco numa das mãos do sujeito uma pedrinha envolta num saquinho de textura macia (dos quais são utilizados para vender legumes). (CLARK, 1980, p. 51 apud ALMEIDA, 2013, p. 73).
}

A partir dos estudos de Almeida(2013) é possível verificar que o que Lygia Clark pretende, com a Estruturação Self, é estabelecer uma profunda reflexão a partir da Memória Corporal e com isso uma conscientização do corpo pelo próprio indivíduo que é submetido à experiência, mas que este ao artista/terapeuta não deve deixar de participar atentamente do processo, 
tendo com isso um papel preponderante na coordenação do mesmo já que deverá está atento à necessidade de estimular o corpo suprimindo os buracos no corpo do indivíduo, expressão esta utilizada pela autora para designar os espaços vazios do corpo que seriam os lugares em que não está havendo contato com nenhum corpo exterior ao indivíduo.

Um dos elementos utilizados nesse processo é uma pedrinha colocada envolta num saquinho de textura macia que segundo a autora é fundamental porque é vivida como um objeto concreto que não é nem o sujeito e nem o mediador da experiência e por está posicionado fora desta relação é chamada de Prova da Realidade ou Prova do Real.

A experiência com o Objeto Relacional é concluída quando é dado ao participante, após ter se levantado e espreguiçado lentamente, sacos plásticos cheios de ar para que sejam manipulados ou eventualmente arrebentados enquanto lhes é feita massagem na cabeça para, segundo Clark, criar condições favoráveis ao acting-out, encorajando assim com que o indivíduo não se veja como culpado, mas que se sinta responsável pela atitude de manusear o Objeto que é tido como finalização da experiência, pois a manipulação e/ou estouro do saco plástico tem um significado simbólico.

Trata-se de vivenciar a - ambivalência - em relação ao objeto. Na destruição o - objeto relacional é um receptáculo para receber os ataques do sujeito, não como um objeto, mesmo parcial (cf. KLEIN, Melanie), mas ainda na indiferenciação: os dois corpos são como vasos comunicantes, continente em que a criança não diferencia o que é ela e o que é o objeto. (CLARK, 1980, p, 52 apud ALMEIDA, 2013, p. 74).

Durante todo o processo não há verbalização dos sentimentos ficando os diálogos restritos ao corpo do indivíduo que ao sentir passa pelo segundo momento de conscientização corporal designado por Clark como o momento em que o corpo passa a ter a consciência de outros corpos que com ele mantém contato, sendo o silêncio fundamental neste momento da experimentação, apenas após o processo é que quem quiser pode expressar verbalmente o que sentiu a partir do contato com os Objetos.

\section{A urgência de uma Pedagogia Teatral a partir da perspectiva do cuidado de si sob a ótica de Gilberto Icle}

Icle (2009) nos traz a reflexão para a necessidade urgente de se pensar a Pedagogia Teatral como cuidado de si a partir do envolvimento em práticas teatrais que não tenham como fim o 83

IAÇÁ: Artes da Cena | Vol. II| n. 2 | ano 2019 
espetáculo e sim o teatro como um fim em si mesmo, numa perspectiva de instigar, as pessoas submetidas às suas práticas, a terem consciência de seus corpos com relação a outros corpos.

Ele busca na origem da Pedagogia Teatral que inicia com Stanyslavski ${ }^{3}$ no seu trabalho de preparação do ator, o processo que fez do teatro uma urgência para as práticas sociais de humanização, afirmando que foi mostrado por diferentes formas que ensinar teatro proporciona o desenvolvimento de aspectos humanos múltiplos e por esse motivo o teatro tem se apresentado, na forma pedagógica, em ambientes tão diferentes quanto empresas, igrejas, associações, ONGs, escolas, presídios, hospitais; reforçando ainda mais a concepção de que a forma privilegiada de sua presença nestes lugares, com objetivos/finalidades de humanização, ou seja, de tornar as pessoas conscientes da importância de cuidarem de si e das pessoas com as quais convivem. Teatro não é apenas a realização de uma obra artística (espetáculo) como fim, mas o processo que levou a este espetáculo, as transformações sociais/humanas que aconteceram durante a montagem do espetáculo.

Para tanto, pergunto: como foi possível que o teatro se desprendesse dos círculos estritamente profissionais para ser desenvolvido como uma prática de si sobre si? Que condições possibilitaram entender o teatro para além do espetáculo e seu processo como terreno para uma "humanização", para uma educação do sujeito, na qual as práticas artísticas do teatro exercem instrumental para melhorar a vida? Como foi possível nos tornarmos sujeitos de uma verdade que pensa o teatro como campo de desenvolvimento humano, como terreno no qual os humanos se tornam sujeitos de seu corpo, de seus afetos e de sua reflexão? (ICLE, 2009, p. 2)

Os Parâmetros Curriculares Nacionais - Artes também se apresentam em conformidade com a proposição de Icle quanto à finalidade do ensino do teatro quando justificam como uma experiência que amplia a capacidade de dialogar, a negociação, a tolerância e a convivência com a ambiguidade (Parâmetros curriculares nacionais: arte /Secretaria de Educação Fundamental. Brasília : MEC /SEF, 1998)

Nos PCN's Ensino Médio também há harmonia de pensamento no que corresponde ao ensino do teatro na escola que não deve restringir-se ao ensino estático da história, dos estilos

\footnotetext{
${ }^{3}$ Moscou, (7 de agosto de 1938) foi um ator, diretor, pedagogo e escritor russo de grande destaque entre os séculos XIX e XX. Stanislavski é mundialmente conhecido pelo seu "sistema" de atuação para atores e atrizes, onde reflete sobre as melhores técnicas de treinamento, preparação e sobre os procedimentos de ensaios. Embora pensadas para o teatro, suas proposituras cênicas são largamente utilizadas por artistas de cinema e televisão.
} 84 
ou da linguagem em separado da prática, devendo-se valorizar as possibilidades de convivência com o outro.

\section{O sentido e a finalidade do cuidado de si buscado por Icle}

A finalidade de Icle quando se propõe a fazer um mergulho na história atrás do conceito de cuidar de si não é encontrar uma verdade estanque, paralisada na história, muito menos buscar uma solução de continuidade; mas chamar a atenção para a necessidade de uma Pedagogia Teatral a partir da necessidade do cuidado de si para a sociedade contemporânea.

Em sua tentativa de procurar entender a necessidade do "cuidar de si", Icle nos remete a diversas indagações do que seria isso a partir do ponto de vista conceitual, se existe ou existiria uma cultura de cuidar de si, se é realmente uma arte da existência na pretensão de tornar o ser humano melhor tal qual o discurso da Pedagogia Teatral professava e se há alguma relação com ela a partir da concepção de Stanislavski, tendo-se esse autor como uma possível fonte de onde o termo originariamente poderia ter sido criado.

Parece sedutor que esse conjunto de questões possa encontrar na análise do trabalho de Stanislavski indícios para sua problematização. Reconhecer como marco histórico o trabalho, as práticas e, sobretudo, os escritos deixados pelo diretor russo, constituem não somente um caminho possível como uma necessidade para a compreensão - ainda que parcial - das questões relativas à Pedagogia Teatral contemporânea. (ICLE, 2009, p. 2)

Para tanto nos lança os questionamentos de, a partir de quando se foi possível pensar o teatro desprendendo-o dos círculos estritamente profissionais para ser desenvolvido como uma prática de si sobre si? Que condições possibilitaram entender o teatro para além do espetáculo e seu processo como terreno para uma "humanização", para uma educação do sujeito, na qual as práticas artísticas do teatro exercem instrumental para melhorar a vida? Como foi possível nos tornarmos sujeitos de uma verdade que pensa o teatro como campo de desenvolvimento humano, como terreno no qual os humanos se tornam sujeitos de seu corpo, de seus afetos e de sua reflexão? (ICLE, 2009)

Esse conjunto de questões, segundo Icle, encontra na análise do trabalho de Stanislavski, indícios para sua problematização a partir do momento que reconhece como marco histórico o trabalho, as práticas e, sobretudo, os escritos deixados por ele como um caminho possível para a

85

IAÇÁ: Artes da Cena | Vol. II| n. 2 | ano 2019 
compreensão, ainda que parcial, das questões relativas à Pedagogia Teatral contemporânea, reconhecendo nesta caminhada rumo a uma defesa da necessidade da Pedagogia Teatral numa perspectiva do cuidar de si, alguns elementos comuns que o faz pensar uma relação ética e estética de si para consigo na contemporaneidade.

Da Pedagogia Teatral a partir de Stanislavski com a intenção de melhorar a eficiência da atuação no seio dos espaços criativos e inventivos do teatro no século $X X$, Icle percebe que outros significados do termo Pedagogia Teatral passa a ter que vão para além do teatro, figurando como urgência de humanização dos sujeitos na vida contemporânea, por intermédio das práticas teatrais com finalidades pedagógicas. Percebe-se aí então uma inversão do termo a partir de sua origem que era voltada para aprimorar o trabalho do ator, mas que talvez também já estivesse sido contemplado por Stanislavski quando pensava numa formação para o ator que, ao mesmo tempo que lhe servisse profissionalmente, também pudesse Ihe servir para a vida.

Essa condição diz respeito, para ele, a uma postura, a um comportamento, a uma disciplina, a um exercício constante sobre si. E qual o si que interessa a Stanislavski? Não é, certamente, o eu do personagem, tampouco o eu narcisista, mas o humano e, por conseguinte, a transformação, a mudança. O si com que se ocupa Stanislavski é o próprio ser humano se revelando para além do ator, para além da profissão. (ICLE, 2009, p. 4)

Icle ainda reforça a necessidade de que o Teatro apresenta diferença para quem o pratica e para quem apenas é espectador, não que este último não passe pela experiência na qual foi exposto, sendo esta uma experiência significativa que possa usufruir de seu conteúdo e inclusive passar por algumas transformações internas, mas que estas transformações serão diferentes das transformações de quem está diretamente envolvido no processo, jogando, atuando, brincando, interpretando, representando a outro que não a si. Neste caso a tomada de consciência, da qual o processo teatral será protagonista, será diferente.

\section{Considerações finais}

A Estruturação do Self como proposta de Clark passa a dar um novo direcionamento ao trabalho do artista no sentido de colocá-lo como um terapeuta que auxilia o indivíduo na tarefa de se conscientizar sobre o seu próprio corpo, instigando-o a atingir as memórias vividas por esse 
corpo por meio de estímulos dos Objetos Relacionais que só passam a ter sentido na relação com o sujeito envolvido na experimentação.

Em função disso pode haver um diálogo com a proposição de Icle no que diz respeito à finalidade do teatro com fins pedagógicos, em que este não deve ser entendido apenas como preparação de espetáculo ou formação de atores, mas também como forma de instigar as pessoas a cuidarem de si no aspecto de adquirirem consciência de suas potencialidades corporais.

Nesse sentido o trabalho com as experiências corporais pode ser desenvolvido com qualquer pessoa independente de ter mais ou menos contato com o teatro no que diz respeito a fazer parte atuando ou sendo mera espectadora.

Compreendeu-se que a Estruturação do Self, trabalho poético de Clark, dialogando com o Cuidado de si proposto por Icle, como proposta pedagógica para o ensino do teatro, só passa a ter sentido se for pensado considerando-se a realidade da escola, as dificuldades que as pessoas ainda têm de lidar com o seu corpo e que por isso passa a ser de fundamental importância que se leve, ainda que de forma gradativa, à escola e a essas pessoas experimentações como estas que contribuam para a consciência corporal.

Com relação à preparação dos Objetos Relacionais, é necessário ter um cuidado/rigor na hora de construí-los no sentido de que possam proporcionar diferentes estímulos de temperatura e de densidade e assim possam estimular os participantes a desencadearem as suas memórias corporais, proporcionando relaxamento ou ajudando-os a superar algum trauma que possam ter vivido e que podem ser despertados por esses estímulos.

A Estruturação do Self pode servir de ponte para a Pedagogia Teatral como "Cuidado de si" pela possibilidade que traz do trabalho de consciência corporal e dessa forma pode vir a instigar a descoberta das potencialidades corporais que são imprescindíveis para uma formação do sujeito independente de ser ator ou não.

\section{REFERÊNCIAS}

ALMEIDA, Eduardo Augusto Alves de. Aspectos da estruturação do self de Lygia Clark: perspectivas críticas. Dissertação (Mestrado - Programa de Pós-Graduação Interunidades em Estética e História da Arte). Universidade de São Paulo. 2013

(Brasil. Secretaria de Educação Fundamental. Parâmetros curriculares nacionais: arte/Secretaria de Educação Fundamental. - Brasília: MEC / SEF, 1998.)

87 
CLARK, Lygia. Lygia Clark. Rio de Janeiro. FUNARTE, 1980.

CLARK, Lygia (com a colaboração de Suely Rolnik), “Objeto Relacional”. In: Lygia Clark (Rio de Janeiro: FUNARTE, coleção ABC, 1980. P.51). Reproduzido In: Manuel J.Borja Villel e Nuria Enguita Mayo (Edit), Lygia Clark (catálogo de exposição), Fondació Antoni Tàpies (Barcelona), Réunion des Musées Nationaux/MAC, galeries contemporaines des Musées de Marseille (Marselha), Fundação de Serralves (Porto) e Palais des Beaux-Arts (Bruxelas), 1997.

GIL, José. Abrir o corpo. In: DISERENS, Corinne; ROLNIK, Suely (orgs). Lygia Clark: da obra ao acontecimento. Somos o molde. A você cabe o sopro. São Paulo: Pinacoteca do Estado de São Paulo, 2006. Catálogo de exposição.

ICLE, Gilberto. Pedagogia teatral como cuidado de si: problematizações na companhia de Foucault e Stanislavski - UFRGS - gicle@uol.com.br GE: Educação e Arte / n.01

ICLE, Gilberto. Da pedagogia do ator à pedagogia teatral: verdade, urgência, movimento. $O$ Percevejo online. 2009

NICASTRO, Sandra. A propósito de revisistar la mirada sobre la escuela: exploraciones acerca de lo ya sabido. Homo Sapiens, 2006.

Orientações curriculares para o ensino médio. Linguagens, códigos e suas tecnologias. ; volume 1. Secretaria de Educação Básica. - Brasília: Ministério da Educação, Secretaria de Educação Básica, 2006. 239 p.

ROLNIK, Suely. Afinal, o que há por tras da coisa corporal. Manuel J.B. Villei e Nuria E. Mayo (Edit.), Lygia Clark, Fondació Antoni Tápies (Barcelona), Réunion des Musées Nationaux/MAC, galeries contemporaines des Musées de Marselle (Marselha), Fundação de Serralves (Porto) e Palais des Beaus-Arts (Bruxelas), 1997; p. 233.

Artigo submetido em 25/01/2019, e aceito em 27/07/2019. 